\title{
Yersinia Species in the Dunnock (Prunella modularis) in Sub-alpine Habitats of the Western Carpathians
}

\author{
JANA KISKOVÁ*, ZUZANA HREHOVÁ, MARIÁN JANIGA, MARTIN LUKÁŇ, MARTINA HAAS \\ and MARTINA JURČOVIČOVÁ
}

Institute of High Mountain Biology, University of Žilina, Tatranská Javorina, Slovakia

Received 29 August 2010, revised 5 December 2010, accepted 15 December 2010

\begin{abstract}
The study presents the prevalence of Yersinia species in dunnok Prunella modularis from the sub-alpine zone of the Western Carpathians. Bacteria were detected from cloacal and pharyngeal swabs from 97 specimens using PCR assay. Yersinia enterocolitica showed the highest prevalence (47.4\%) from among the determined Yersinia species. Yersinia species (except Y. frederiksenii) were detected more frequently in pharyngeal than cloacal samples. The highest prevalence of yersiniosis was detected in April (Yersinia spp. - 80\%, Y. enterocolitica $-70 \%$ ). No statistically differences were observed in the prevalence of Yersinia spp. between males and females and between juveniles and adult birds. Bacterial contamination did not affect body weight or tarsus length.
\end{abstract}

K e y w ord s: Yersinia spp. Yersinia enterocolitica, Dunnock Prunella modularis

The genus Yersinia is a highly heterogeneous group of the family Enterobacteriaceae comprising acknowledged pathogens and a variety of strains that are widely distributed in nature in both aquatic and terrestrial ecosystems (Cover and Aber, 1989). Many species such as Yersinia enterocolitica are psychrophilic bacteria capable of persisting and growing in cold environments (Kato et al., 1985; Gill and Reichel, 1989).

The wild-living birds, due to their great mobility, may play a significant role as effective spreaders of Yersinia through faecal contamination of pastures and surface waters (Kaneuchi et al., 1989; Niskanen et al., 2003).

There are only a few studies on bacteria living in wild birds in the extreme environments of the subalpine and alpine vegetation levels. Janiga et al. (2007) identified the composition of microflora in the digestive tract of the alpine accentor (Prunella collaris) as a typical species of alpine environments. Novotný et al. (2007) specifically discussed the ecology of Yersinia spp. in relation to alpine accentors considering that the genus Yersinia may play an important role in the ecology of this bird species.

The objective of this study was to continue research of yersiniosis in lower sub-alpine habitats in the West
Carpathians. The dunnock (Prunella modularis) is a dominate bird species of the dwarf-pine ecosystem (950-1 $700 \mathrm{~m}$ a.s.l) and as the alpine accentor is the member of the family Prunellidae, therefore it was chosen as experimental host species for this microbiological study.

From April 2007 to July 2009, 97 free-living dunnocks were captured with mist nets in the local mountains of the Slovakian part of the Western Carpathians - The West, High, Low and Belianske Tatras, Great and Small Fatra, Babia hora, and Choč (from 1000 to $1750 \mathrm{~m}$ a.s.l). Captured birds were identified as adults or juveniles (age $\leq 2$ months). Adult birds were sexed by the presence of a cloacal protuberance in males (Nakamura, 1990). They were weighed with $0.2 \mathrm{~g}$ accuracy using a Pesola spring scale and standard morphometric measurements were taken. Two types of samples were collected from each bird - pharyngeal and cloacal swabs. Samples were taken using sterile transport swabs suitable for both aerobes and anaerobes (DispoLab, Copan Italia, Brescia, Italy).

Isolated bacterial cultures from cloacal and pharyngeal swabs were enriched in Tryptone-soya broth at $26-28^{\circ} \mathrm{C}$ for 48 hours (Nikolova et al., 2001). Enriched

* Corresponding author: J. Kisková, Institute of High Mountain Biology, Tatranská Javorina 7, 059 56, Slovakia; phone: (+421) 51-449-91-08; e-mail: jakiskova@gmail.com 
cultures were plated on CIN agar presented as highly selective medium for Yersinia spp. (Schiemann, 1979) and cultivated at $26-28^{\circ} \mathrm{C}$ for 48 hours (Neubauer et al., 2000; Hussein et al., 2001).

Bacterial DNA was extracted and then Yersinia species were identified among isolated bacterial cultures using the PCR method developed by Neubauer et al. (2000). The authors designed primers Y1 and Y2 for amplification of the specific region of the 16S rRNA gene of the genus Yersinia. Primers A1 and A2 were used to amplify a $430 \mathrm{bp}$ fragment of the ail gene, found exclusively in pathogenic Yersinia spp. strains (Wannet et al., 2001). For the identification of Yersinia spp. a reference strain (CCM 5671) of $Y$. enterocolitica subsp. enterocolitica, serovar 0:3, biovar 4 was obtained from the Czech collection of microorganisms, Masaryk University, Brno. The PCR products were independently sequenced in both directions on the Genome Lab GeXP Single genetic analyzer (Beckman Coulter Inc.) The obtained sequences were subjected to BLAST searches in sequence database GenBank for species identification.

$Y$. pseudotuberculosis was also independently examined in all samples. The AmpliSens Yersinia pseudotuberculosis kit (Russia) was used for the identification.

A $\chi^{2}$ statistics (STATISTICA 8.0) was used to test the hypothesis of independence of frequencies of selected factors (prevalence, sex, age and season) which may influence the occurrence of bacteria. Morphometric data were compared by one-way ANOVA.
From 97 examined birds, a total of $47.4 \%$ individuals were Yersinia positive (28.9\% of pharyngeal and $27.8 \%$ of cloacal samples). Seven Yersinia species were detected by comparison of PCR-product's to the nucleotide sequences in BLAST (GenBank, Table I). $Y$. enterocolitica showed the highest total incidence $(34.0 \%)$ of the genus Yersinia, therefore it is considered in this study as separate species. The higher prevalence of $Y$. enterocolitica tended to be in cloacal $(20.6 \%)$ than in pharyngeal $(16.5 \%)$ samples. Also other Yersinia species (except Y. fredericksenii) were detected more frequently in pharyngeal than cloacal swabs. The differences were not statistically significant.

A seasonal variation in the distribution of Yersinia spp. was observed. The highest prevalence of Yersinia species was detected in April (80\%). Even, the contamination of $Y$. enterocolitica reached a statistically significant value compared to other months $(\mathrm{P} \leq 0.05)$, in which the prevalence of bacteria decreased significantly (Table II).

Comparison of the total prevalence of Yersinia spp. between males and females did not show significant differences but in females was nearly $10 \%$ higher than in males. A much lower frequency of infection in juveniles than in adult individuals was found but the difference didn't reach the statistical significance value ( $\mathrm{P} \geq 0.05$, Table II).

Table III shows the potential relation between the occurrence of Yersinia spp., resp. Y. enterocolitica and morphological features of the adult birds. Measurements of body weight and tarsus length were

Table I

Species and prevalence of pharyngeal and cloacal bacteria in Dunnocks in the Western Carpathians, Slovakia

\begin{tabular}{|c|c|c|c|c|}
\hline \multirow[b]{2}{*}{ Bacteria species } & \multirow{2}{*}{$\begin{array}{l}\text { Strain according } \\
\text { GenBank }\end{array}$} & \multicolumn{3}{|c|}{ Prevalence $(\mathrm{n}=97)$} \\
\hline & & $\begin{array}{l}\text { Total } \\
\text { N (\%) }\end{array}$ & $\begin{array}{c}\text { Pharynx } \\
\text { N (\%) }\end{array}$ & $\begin{array}{l}\text { Cloaca } \\
\text { N }(\%)\end{array}$ \\
\hline Yersinia spp. & & $46(47.4)$ & $28(28.9)$ & $27(27.8)$ \\
\hline Y. enterocolitica & $\begin{array}{l}8081 \\
\text { FE } 80735 \\
\text { KM } 1 \\
\text { PO/Y/1-3 } \\
\text { ARCTIC-P11 }\end{array}$ & $33(34.0)$ & $20(20.6)$ & $16(16.5)$ \\
\hline Y. kristensenii & $\begin{array}{l}\text { ATCC } 33638 \\
\text { N1SF35 } \\
\text { Y } 160\end{array}$ & $10(10.3)$ & $10(10.3)$ & $6(6.2)$ \\
\hline Y. molareti & H279-36/86 & $2(2.1)$ & $2(2.1)$ & $1(1)$ \\
\hline Y. intermedia & $\begin{array}{l}\text { H9-36/83 } \\
253\end{array}$ & $2(2.1)$ & $2(2.1)$ & $0(0)$ \\
\hline Y. aleksici & $\begin{array}{l}991 \\
\text { Y } 388\end{array}$ & $2(2.1)$ & $2(2.1)$ & $0(0)$ \\
\hline $\begin{array}{l}\text { Y. bercovieri } \\
\text { Y. frederiksenii }\end{array}$ & $\begin{array}{l}\text { H632-36/85 } \\
\text { WS 52/02 }\end{array}$ & $\begin{array}{l}2(2.1) \\
2(2.1)\end{array}$ & $\begin{array}{l}2(2.1) \\
0(0)\end{array}$ & $\begin{array}{l}1(1.0) \\
2(2.1)\end{array}$ \\
\hline
\end{tabular}

$\mathrm{n}$ - number of examined birds

$\mathrm{N}$ - number of Yersinia positive samples with relative value in the brackets 
Table II

The prevalence of bacterial genera (species) in dunnocks according to the season years, the host sex and age

\begin{tabular}{|c|c|c|c|c|}
\hline & Variable (n) & $\begin{array}{c}\text { Yersinia positive } \\
\mathrm{N}(\%)\end{array}$ & $\begin{array}{c}\text { Yersinia negative } \\
\mathrm{N}(\%)\end{array}$ & $\mathrm{P}$ \\
\hline \multirow[t]{4}{*}{ Y. enterocolitica } & April (10) & $7(70)$ & $3(30)$ & \multirow{4}{*}{0.03} \\
\hline & May (32) & $13(40.6)$ & $19(59.4)$ & \\
\hline & June (25) & $6(24)$ & $19(76)$ & \\
\hline & July (30) & $7(23.3)$ & $23(76.7)$ & \\
\hline \multirow[t]{4}{*}{ Yersinia spp. } & April (10) & $8(80)$ & $2(20)$ & \multirow{4}{*}{ NS } \\
\hline & May (32) & $15(46.9)$ & $17(53.1)$ & \\
\hline & June (25) & $10(40)$ & $15(60)$ & \\
\hline & July (30) & $13(43.3)$ & $17(56.7)$ & \\
\hline \multirow[t]{2}{*}{ Y. enterocolitica } & Females (45) & $17(37.8)$ & $28(62.2)$ & \multirow{2}{*}{ NS } \\
\hline & Males (35) & $13(37.1)$ & $22(62.9)$ & \\
\hline \multirow[t]{2}{*}{ Yersinia spp. } & Females (45) & $25(55.6)$ & $20(44.4)$ & \multirow{2}{*}{ NS } \\
\hline & Males (35) & $16(45.7)$ & $19(54.3)$ & \\
\hline \multirow[t]{2}{*}{ Y. enterocolitica } & Adults (80) & $30(37.5)$ & $50(62.5)$ & \multirow{2}{*}{ NS } \\
\hline & Juveniles (17) & $3(17.7)$ & $14(82.4)$ & \\
\hline \multirow[t]{2}{*}{ Yersinia spp. } & Adults (80) & $41(51.3)$ & $5(29.4)$ & \multirow{2}{*}{ NS } \\
\hline & Juveniles (17) & $39(48.8)$ & $12(70.6)$ & \\
\hline
\end{tabular}

$\mathrm{n}$ - number of examined birds

$\mathrm{N}$ - number of Yersinia positive $(+)$ or negative $(-)$ samples with relative value in the brackets $\mathrm{NS}$ - not significant $\mathrm{P}>0.05$ (Chi-square test)

Table III

Morphological characters of adult dunnocks examined for yersiniosis

\begin{tabular}{|c|c|c|c|c|c|}
\hline Bacteria & $\begin{array}{l}\text { Morphological } \\
\text { variables }\end{array}$ & $\begin{array}{c}\text { Yersinia } \\
+/-\end{array}$ & $\begin{array}{c}\text { Number of adult } \\
\text { individuals }\end{array}$ & Mean $\pm \mathrm{SE}$ & $\mathrm{P}$ \\
\hline \multirow[t]{4}{*}{ Y. enterocolitica } & \multirow[t]{2}{*}{ Body weight (g) } & + & 25 & $19.7 \pm 0.8$ & \multirow{2}{*}{ NS } \\
\hline & & - & 46 & $19.1 \pm 0.6$ & \\
\hline & \multirow[t]{2}{*}{ Tarsus length $(\mathrm{mm})$} & + & 29 & $24.9 \pm 0.2$ & \multirow{2}{*}{ NS } \\
\hline & & - & 48 & $24.8 \pm 0.1$ & \\
\hline \multirow[t]{4}{*}{ Yersinia spp. } & \multirow[t]{2}{*}{ Body weight (g) } & + & 34 & $19.6 \pm 0.7$ & \multirow{2}{*}{ NS } \\
\hline & & - & 37 & $19.1 \pm 0.6$ & \\
\hline & \multirow[t]{2}{*}{ Tarsus length (mm) } & + & 39 & $24.8 \pm 0.2$ & \multirow{2}{*}{ NS } \\
\hline & & - & 38 & $24.9 \pm 0.2$ & \\
\hline
\end{tabular}

$\mathrm{NS}$ - not significant, $\mathrm{P}>0.05$ (one - way ANOVA test)

considered. No significant relationships were found between the Yersinia spp., resp. Y. enterocolitica infection and tarsus length or body weight of hosts.

When the dunnock sex and infestation by yersiniosis were considered as independent variables, no statistically significant difference was found in prevalence of Yersinia between males and females (Table II). Therefore, both sexes were pooled together and tested against Yersinia as one group.

Y. pseudotuberculosis was not detected in any of pharyngeal and cloacal swabs. The presence of the ail gene associated with the pathogenic strains of Yersinia was not confirmed in any of the examined samples.

Recently, PCR method is widely used to identify specimens and studying the relationship of bacteria.
However, the target sequences of both primers Y1 and Y2 using in this study are presented in more members of the genus Yersinia; it was possible to determinate more Yersinia species by using only one PCR array (Neubauer et al., 2000).

In this study, a lower occurrence of yersiniosis was found in subalpine habitats compared to the alpine zone in previous study (Novotný et al., 2007). The authors showed that in alpine accentors there is an unusually high prevalence of yersiniosis in comparison to many other bird species. The authors attribute this to high adaptability of Yersinia species to cold environment. For example, Gill and Reichel (1989) referred to the ability of $Y$. enterocolitica to grow at $-2^{\circ} \mathrm{C}$. This might be the reason for its successful 
expansion in high mountain environments and for its higher prevalence in alpine accentors than in dunnocks. In this study we have confirmed that $Y$. enterocolitica is the most common yersinia in dunnocks in comparison with other Yersinia species. Similar findings were reported in other species of birds (Niskanen et al., 2003; Novotný et al., 2007). Also other species of Yersinia (no pathogenic environmental species e.g. Y. intermedia, Y. frederiksenii or Y. kristenseni ect.) were frequently found in other species of birds (Niskanen et al., 2003; Janiga et al., 2007).

As our results show that distribution of yersiniosis in dunnock is seasonally dependent. Prevalence of avian bacterial infections is known to have seasonal dynamics where social and other behaviours have been hypothesized to be a factor shaping these dynamics (Faustino et al., 2004). The high occurrence of $Y$. enterocolitica in cold months was confirmed in many studies. For example, Kato et al. (1985) reported significantly higher incidence of $Y$. enterocolitica in birds in the spring than in the summer or autumn months. The highest prevalence of all Yersinia species in the dunnock was detected in April. In this month, the dunnock breeding season begins and birds begin to mate. Avian copulation involves cloacal contact, which has been documented to host rich bacterial communities (Lombardo, 1998; Lucas and Heeb, 2005). So, the risks of bacterial transmission during copulations in birds are expected to be high. Dunnocks have a variable mating system from monogamy through polyandry to polygynandry (Davies, 1985) and copulation with multiple partners further increases the risk of avian infection. It seems bird diet may also influence the occurrence of bacterial infection. The dunnock is an insectivorous species and in April, when the occurrence of insects increases in the mountains, the risk of infection is higher. In the next months (outside the mating period) the prevalence of bacterial infection declines gradually. In July, when the juveniles have left the nests, the bacterial infection may be slightly increased again. This phenomenon is probably associated with reduced body condition of birds. The birds are exhausted after breeding and subsequent moulting may also have a significant impact on the physiological status of the individuals.

Colonisation of nestlings by environmental microbes begins soon after hatching. Mills et al. (1999) detected cloacal microorganisms in nestlings of the tree swallow (Tachycineta bicolour) two days after hatching. The inoculation of nestlings by microbes may occur from the environment via ingestion of adult saliva, from food provided by the parents or from nest materials (Mills et al., 1999; Berger et al., 2003). In our study, we detected about $20 \%$ fewer contamination of Yersinia in juveniles than in adult birds. The low infection of juveniles during whole research period indicates that infection of juveniles by Yersinia occurs later. We therefore suggest that young birds are infected by bacteria mainly during the breeding season in the following year.

To conclude, we confirmed that the prevalence of bacterial infections in dunnocks shows seasonal dynamics. In early spring, the high occurrence of Yersinia contamination may be associated with changes in diet, but is most likely a consequence of the increased risk of contamination during mating. We observed that the sex of birds did not influence the distribution of Yersinia spp. in the dunnock and that bacterial occurrence in birds increases with nestling age and stabilizes in adults. We didn't found relationship between morphological parameters (tarsus length and body weight) and Yersinia infestation, therefore we assume that bacteria do not affect health and body condition of individuals. Our findings support the idea that the Yersinia species are surely a common member of bacterial microflora in dunnocks.

\section{Literature}

Berger S., R. Disko and H. Gwinner. 2003. Bacteria in starling nests. J. Ornithol. 144: 317-322.

Cover T.L. and R.C. Aber. 1989. Yersinia enterocolitica. New Engl. J. Med. 321: 16-24.

Davies N.B. 1985. Cooperation and conflict among dunnocks, Prunella modularis, in variable mating system. Anim. Behav. 33: 628-648

Faustino C.R., C.S. Jennelle, V. Connolly, A.K. Davis, E.C. Swarthout, A.A. Dhondt and E.G. Cooch. 2004. Mycoplasma gallisepticum infection dynamics in a house finch population: seasonal variation in survival, encounter and transmission rate. J. Anim. Ecol. 73: 651-669.

Gill C.O. and M.P. Reichel. 1989. Growth of the cold-tolerant pathogens Yersinia enterocolitica, Aeromonas hydrophila and Listeria monocytogenes on high-pH beef packaged under vacuum or carbon dioxide. Food Microbiol. 6: 223-230.

Hussein H.M., S.G. Fenwick and J.S. Lumsden. 2001. A rapid and sensitive method for the detection of Yersinia enterocolitica strains from clinical samples. Lett. Appl. Microbiol. 33: 445-449.

Janiga M., A. Sedlárová, R. Rigg and M. Novotná. 2007. Patterns of prevalence among bacterial communities of Alpine Accentors (Prunella collaris) in the Tatra Mountains. J. Ornithol. 148: 135-143.

Kaneuchi Ch., M. Shibata, T. Kawasaki, T. Kariu, M. Kanzaki and T. Maruyama. 1989. Occurrence of Yersinia spp. in migratory birds, ducks, seagulls and swallows in Japan. Jpn. J. Vet. Res. 51: 805-808.

Kato Y., K. Ito, Y. Kubokura, T. Maruyama, K. I. Kaneko and M. Ogawa. 1985. Occurrence of Yersinia enterocolitica in wild-living birds and Japanese Serows. Appl. Env. Microbiol. 49: 198-200.

Lombardo M.P. 1998. On the evolution of sexually transmitted diseases in birds. J. Avian Biol. 29: 314-321.

Lucas F.S. and P. Heeb. 2005. Environmental factors shape cloacal bacterial communities in great and blue tit nestlings. J. Avian Biol. 36: 510-516.

Mills T.K., M.P. Lombardo and P.A. Thorpe. 1999. Microbial colonization of the cloacae of nestling tree swallows. Auk 116: 947-956. 
Nakamura M. 1990. Cloacal protuberance and copulation behavior of the Alpine Accentor (Prunella collaris). Auk 107: 284-295.

Neubauer H., A. Hensel, S. Aleksic and H. Meyer. 2000. Identification of Yersinia enterocolitica within the genus Yersinia. Sys. Appl. Microbiol. 23: 1-5

Nikolova S., Y. Tzvetkov, H. Najdenski and A. Vesselinova. 2001. Isolation of pathogenic Yersiniae from wild animals in Bulgaria. J. Vet. Med. 48: 203-209.

Niskanen T., J. Waldenström, A.M. Fredriksson, B. Olsen and H. Korkeala. 2003. virF-Positive Yersinia pseudotuberculosis and Yersinia enterocolitica found in migratory birds in Sweden. Appl. Env. Microbiol. 69: 4670-4675.

Novotný M., M. Fečková, M. Janiga, M. Lukáň, M. Novotná and Z. Kovalčíková. 2007. High incidence of Yersinia enterocolitica (Enterobacteriaceae) in Alpine Accentors Prunella collaris of the Tatra Mountains. Acta Ornithol. 42: 137-143

Schiemann D.A. 1979. Synthesis of a selective agar medium for Yersinia enterocolitica. J. Microbiol. 25:1298.

Wannet W.J.B., M. Reessink, H.A. Brunings and H.M.E. Maas. 2001. Detection of pathogenic Yersinia enterocolitica by rapid and sensitive duplex PCR Assay. J. Clin. Microbiol. 39: 4483-4486. 